\title{
Is the emergency readmission rate a valid outcome indicator?
}

\author{
G C Leng, D Walsh, F G R Fowkes, C P Swainson
}

\begin{abstract}
Objectives-The principal aim was to determine whether the emergency readmission rate varies between medical specialties, and to identify whether differences in emergency readmission rates between hospital trusts can be reduced by standardising for specialty. Possible factors influencing emergency readmission were also investigated, including frequency of previous admission and cause of readmission.
\end{abstract}

Design-Emergency readmission rates were obtained from the Scottish Morbidity Record scheme (SMR1) using record linkage, standardised for age and sex. Rates throughout Scotland were analysed by specialty, and rates for general medicine compared among teaching hospital trusts. Cause of emergency readmission was determined from hospital records in a random sample (177 patients).

Setting-Medical specialties throughout Scotland.

Subjects-All patients readmitted as an emergency within 28 days of discharge (October 1990 to September 1994).

Department of

Primary Care and

Population Sciences,

Royal Free and

University College

Medical School,

London, UK

G C Leng, clinical lecturer

in epidemiology

Information and Statistics Division,

Edinburgh, UK

D Walsh, health

information analyst

Wolfson Unit for Prevention of

Peripheral Vascular

Diseases, University of

Edinburgh, UK

F G R Fowkes, professor of

epidemiology

The Royal Infirmary of Edinburgh NHS Trust, UK

C P Swainson, medical

director

Correspondence to:

Dr G Leng, Department of

Primary Care and Population

Sciences, Royal Free and

University College Medical

School, Rowland Hill Street,

London NW3 2PF, UK

Accepted 10 August 1999
Results-Emergency readmissions varied markedly between medical specialties, with highest rates in nephrology $(24.2 \%$, $95 \%$ CI 23.5 to 24.8 ) and haematology (20.4\%, 95\% CI 19.9 to 20.9$)$, and the lowest in homeopathy $(2.2 \%, 95 \%$ CI 1.6 to $2.7)$ and metabolic diseases $(3.5 \%, 95 \%$ CI 2.4 to 4.5 ). The largest number of emergency readmissions was in general medicine, accounting for $63 \%$ of the total. Restricting emergency readmission rates to general medicine significantly altered previous rates. In the year preceding the emergency readmission, $59 \%$ of all patients had been admitted to hospital at least once, and most emergency readmissions $(73.3 \%)$ resulted from a chronic underlying condition.

Conclusions-Significant variations in emergency readmission rates occurred between medical specialties, suggesting that differences between hospital trusts are influenced by differences in specialties and thus case mix. The majority of emergency readmissions occurred in patients with an underlying chronic condition, and many had a history of multiple previous hospital admissions. The emergency readmission rate is therefore unlikely to be a valid outcome indicator reflecting quality of care until routine data are available for standardisation by case mix.
(Quality in Health Care 1999;8:234-238)

Keywords: emergency readmission rates; outcome indicators; specialty mix

Trends in readmissions

Recent years have seen rises in readmissions both in the UK ${ }^{1-5}$ and the US. ${ }^{6}$ In Oxfordshire, readmission rates almost doubled between 1968 and 1985, with a $75 \%$ increase in emergency readmissions. ${ }^{4} \mathrm{~A}$ similar rise was also seen in Scotland, where the overall readmission rate rose from $7.1 \%$ in 1982 to $11.4 \%$ in $1994 .{ }^{78}$ Unfortunately, the definition of readmission has varied considerably between many studies, including the time since discharge before readmission, and the type of readmission (elective or emergency). This paper focuses on unplanned, or emergency, readmissions.

The rising trend in emergency readmissions is worrying partly because of implications about quality of care but also because of the burden placed on provision of hospital services. Reasons for the increase are less clear and are likely to be complex. ${ }^{3}$ Possible explanations include changes in the social and demographic structure of the population, falling lengths of stay, ${ }^{9}$ and the medical condition itself. ${ }^{10}$ The increasing number of elderly people in the population may be particularly important in generating the rise because admission rates increase dramatically with age, ${ }^{10}{ }^{11}$ especially in those living alone. ${ }^{10} 12$ It has also been suggested that readmissions are related to recurring medical problems, indicated by a higher than expected number of admissions in the period before the readmission. ${ }^{13}$ Recent

- 1983: theme of care in the community for patients with mental health problems began, with closure of many large institutional hospitals

- 1990: NHS and Community Care Act appeared, proposing the purchaserprovider split, the internal market in health care, and GP fundholding. Pressure to reduce costs and length of stay

- 1991/2: emphasis on quality and performance management in the NHS, for example hospital league tables

- 1997: The New NHS: Modern, Dependable (government white paper) heralded the end of the internal market, with the introduction of new primary care groups to replace fundholding. Focus on high quality services and monitoring of performance

Box 1 Key recent organisational changes in the NHS 
changes within the NHS (box 1) have also been blamed for the rising number of readmissions, ${ }^{11}$ including a trend towards shorter hospital stays, plus a drive towards communiy care. ${ }^{9}$

\section{Emergency readmission rate as an outcome indicator}

The emergency readmission rate is also of interest because of its potential use as an outcome indicator. Outcome indicators aim to provide information about patients and their health, as a measure of how far the process of hospital care has achieved its objective. ${ }^{14}$ Ideally, outcome indicators should directly measure genuine service objectives ${ }^{14} 15$ and avoid the development of "perverse incentives", such as clinicians being encouraged not to readmit patients who should be in hospital to manipulate the emergency readmission rate. ${ }^{16}$ General problems with outcome indicators include: errors in hospital data; random variation due to small numbers; variation among hospitals in case mix and severity; and problems in defining the denominator, ${ }^{16}$ some of which inevitably apply to emergency readmission rates.

In 1994, the emergency readmission rate was selected as one of seven outcome indicators for acute hospitals throughout Scotland, ${ }^{7}$ on the assumption that many emergency readmissions would not have occurred if the preceding quality of care had been adequate. Of the seven outcome indicators, the emergency readmission rate provoked most interest partly because of the continuing upward trend but also because marked differences among hospital trusts implied underlying differences in care.

Avoiding readmission is not a direct objective of hospital care, however, and at best the emergency readmission rate acts as a proxy measure of avoidable adverse outcome of the initial admission. At worst it may give a false impression if, for example, improved medical care lowered the threshold for readmission, thus raising emergency readmission rates. If the emergency readmission rate is a valid outcome indicator, a high proportion of these readmissions should be preventable, but the best estimates of avoidability suggest that this represents only $16.5 \%{ }^{17}$ to $18.0 \%{ }^{18}$ of readmitted patients.

Emergency readmission rates in Scotland The structure in Scotland is slightly different from that of England and Wales (box 2). The high quality of routine hospital data collected in

- Scotland is divided into 14 health board areas, each with a population of approximately 500000

- Health boards are equivalent to health authorities in England and Wales, with a responsibility for the health and health care of the local population

- There are six teaching hospital trusts in Scotland, divided between the four main cities: Aberdeen, Dundee, Edinburgh, and Glasgow

Box 2 The Scottish health service
- Uses probability matching to link records, allowing discrepancies in identifying information to be overcome

- Produces a profile for an individual patient by drawing together records from individual hospital episodes, from different SMR schemes, and from death records

- Linkage accuracy estimated to be 98$99 \%$

Box 3 The Scottish record linkage system

Scotland facilitates the study of emergency readmission rates. Data on individual patients are collated within the Scottish Morbidity Record scheme (SMR), the first and largest of which (SMR1) covers hospital inpatient statistics. SMR1 is episode based and relates to all patients discharged from non-psychiatric, nonobstetric wards in Scottish hospitals. Characteristics of an SMR record are that it is: identifiable to an individual patient; based upon a discrete episode; and captures diagnostic and procedures data. It also includes information on the patient, administrative details including the hospital and consultant in charge, and clinical details on diagnosis and operations. In addition to being completed on discharge, a new SMR1 record is also generated every time a patient is transferred between consultants, specialties, or hospitals, thus a single spell in hospital may be recorded by several SMR1 records. To produce a record for an individual patient, rather than for a hospital episode, a technique known as record linkage is used (box 3 ).

\section{Aims of investigation}

Previous studies of emergency readmissions have concentrated on identifying the underlying factors associated with readmission, rather than on its use as an outcome indicator. There have been no reports on variation in emergency readmission rates by medical specialty, and therefore the impact of specialty mix on the overall readmission rate is not known.

The principal aim of this investigation was therefore to determine whether the emergency readmission rate varies between different medical specialties, and to identify whether any of the differences in emergency readmission rates between hospital trusts can be reduced by standardising for specialty. An additional analysis was done in the trust with the highest rates to determine the frequency of previous hospital admissions and the relationship between cause of admission and subsequent emergency readmission. These results would identify some of the important factors influencing emergency readmissions, and indicate whether the emergency readmission rate is likely to be a valid outcome indicator.

\section{Methods}

CALCULATION OF EMERGENCY READMISSION RATES

There is currently no universally accepted definition of an emergency readmission. In general, however, "emergency" is taken to 
Table 1 Emergency readmissions within 28 days by specialty throughout Scotland, October 1990 to September 1994. Rates standardised by age and sex, highest rates given first

\begin{tabular}{|c|c|c|c|}
\hline Medical specialty & Total admissions & $\begin{array}{l}\text { Readmissions } \\
\text { within } 28 \text { days }\end{array}$ & $\begin{array}{l}\text { Standardised rate (\%) } \\
\text { (95\% confidence intervals) }\end{array}$ \\
\hline All specialties & 856780 & 93660 & 10.9 (10.9 to 11.0$)$ \\
\hline Nephrology & 17137 & 4062 & 24.2 (23.5 to 24.8$)$ \\
\hline Haematology & 26715 & 5364 & 20.4 (19.9 to 20.9$)$ \\
\hline Poisons unit & 1182 & 181 & $16.8(14.7$ to 19.0$)$ \\
\hline Respiratory & 50287 & 7267 & $14.1(13.8$ to 14.4$)$ \\
\hline Medical oncology & 12771 & 1721 & $13.6(13.0$ to 14.2$)$ \\
\hline Other acute & 5912 & 720 & $11.8(10.9$ to 12.6$)$ \\
\hline General practice & 67272 & 7588 & $11.2(11.0$ to 11.4$)$ \\
\hline General medicine & 563317 & 59362 & $10.4(10.4$ to 10.5$)$ \\
\hline Infectious diseases & 37141 & 3035 & $9.6(9.3$ to 9.9$)$ \\
\hline Gastroenterology & 9990 & 869 & $8.6(8.1$ to 9.2$)$ \\
\hline Cardiology & 36550 & 2429 & $6.6(6.3$ to 6.8$)$ \\
\hline Rheumatology & 7698 & 364 & $4.8(4.3$ to 5.2$)$ \\
\hline Dermatology & 16951 & 601 & $3.8(3.5$ to 4.1$)$ \\
\hline Metabolic disease & 1208 & 41 & 3.5 (2.4 to 4.5$)$ \\
\hline Homeopathy & 2649 & 56 & $2.2(1.6$ to 2.7$)$ \\
\hline
\end{tabular}

mean non-elective (unplanned), and "readmission" to indicate a second admission within a certain period of previous discharge. For this study, the emergency readmission rate was defined as the proportion of continuous inpatient stays for which there was an emergency or non-elective readmission to inpatient care within 28 days of discharge from a medical specialty. Rates were provided by the Information and Statistics Division of the Scottish Office for the period October 1990 to September 1994, calculated from the SMR1 using record linkage. The accuracy of SMR records, compared with medical records, is estimated to range from $84.9 \%$ to $91.9 \%{ }^{7}$ The linked dataset was used to calculate emergency readmission rates at hospital and medical specialty level. Rates were standardised for age and sex using indirect standardisation to the Scottish population for whom emergency readmission rates were calculated. The analysis of the data began in 1996 and was completed in 1997.

Patients were allocated to the specialty and provider unit of the final episode in the initial stay, not the emergency readmission stay. Provider units were defined as hospital trusts and directly managed units as constituted on 1 July 1995. Where a constituent hospital closed before that date, figures for that hospital were not included. Cases where patients were discharged dead or where death occurred within 28 days of discharge were excluded from the analysis.

ANALYSIS BY MEDICAL SPECIALTY

Emergency readmission rates were initially calculated throughout Scotland as a whole for all medical specialties independently, including: general medicine, cardiology, metabolic disease, gastroenterology, poisons unit, nephrology, rheumatology, homeopathy, medical oncology, haematology, dermatology, respiratory medicine, infectious diseases, general practice, and other acute medical specialties.

Further analysis was restricted to the six teaching hospital trusts in Scotland, to increase comparability among hospital trusts. Overall emergency readmission rates in the teaching hospital trusts were compared, then restricted to rates in general medicine to show the effect of removing specialty mix.
NUMBER OF PREVIOUS ADMISSIONS

In teaching hospital trust $\mathrm{D}$, where the emergency readmission rate was highest, the number of previous admissions was examined for patients readmitted as an emergency during 1992. The number of previous admissions in the previous year and the previous five years was determined from the SMR scheme for all patients with an emergency readmission after discharge from general medicine. This specialty was selected because it had the highest number of readmissions. The principal diagnosis of the admission before the 1992 readmission was also obtained.

ASSOCIATION BETWEEN EMERGENCY READMISSION AND PREVIOUS ADMISSION

A random 1 in 10 sample was selected of all patients readmitted within 28 days of discharge from a medical specialty in teaching hospital trust D, between 1 January and 30 September 1994. This period was selected as the most recent nine month period of the Clinical Resource and Audit Group (CRAG) report. ${ }^{7} \mathrm{~A}$ total of 177 patients were included in the sample, but unfortunately one set of records was untraceable and therefore could not be reviewed.

Details of all SMR1 episodes between 1981 and 1994 were provided for these patients by the information and statistics division. Additional information was sought from case notes for all patients included in the sample, to determine the association between the emergency readmission and the previous admission. Each emergency readmission was categorised by one of the authors (GCL) and by an independent, blinded, observer. Any disagreements were resolved by discussion. The categories of emergency readmission were as follows:

- Unrelated: emergency readmission due to completely different diagnosis from previous admission, for example myocardial infarction followed by a head injury

- Complication: emergency readmission due to complication of treatment at the previous admission, for example nosocomial infection, peritonitis due to continuous ambulatory peritoneal dialysis, reaction to chemotherapy

- Related: emergency readmission with the same problem or with a manifestation of the same underlying chronic condition, for example coronary heart disease, leukaemia

- Self harm: emergency readmission and admission both due to deliberate self harm, including overdose and other causes of attempted suicide.

Table 2 Emergency readmission rates within 28 days for teaching trusts throughout Scotland, October 1990 to September 1994, standardised by age and sex

\begin{tabular}{lcc}
\hline Teaching trust & $\begin{array}{l}\text { All medical specialties } \\
\text { (95\% confidence } \\
\text { intervals) }\end{array}$ & $\begin{array}{l}\text { General medicine (95\% } \\
\text { confidence intervals) }\end{array}$ \\
\hline $\mathrm{A}$ & $10.1(9.9$ to 10.4$)$ & $9.3(9.0$ to 9.7$)$ \\
$\mathrm{B}$ & $9.5(9.2$ to 9.7$)$ & $11.1(10.8$ to 11.5$)$ \\
$\mathrm{C}$ & $11.4(11.1$ to 11.6$)$ & $9.1(8.8$ to 9.4$)$ \\
$\mathrm{D}$ & $13.4(13.2$ to 13.7$)$ & $12.4(12.1$ to 12.7$)$ \\
$\mathrm{E}$ & $9.9(9.5$ to 10.3$)$ & $10.4(9.8$ to 11.0$)$ \\
$\mathrm{F}$ & $12.4(12.2$ to 12.7$)$ & $11.0(10.7$ to 11.4$)$ \\
\hline
\end{tabular}


Table 3 Number of previous admissions in patients readmitted as an emergency to teaching hospital trust $D$ during 1992. All admissions before the emergency readmission were to general medicine

\begin{tabular}{llllc}
\hline \multicolumn{5}{l}{ Number of previous admissions (\%) } \\
\cline { 2 - 5 } & 0 & $1-2$ & $3-4$ & $5+$ \\
\hline In previous year & $419(41.0)$ & $388(38.0)$ & $120(11.8)$ & $94(9.2)$ \\
In previous five years & $183(17.9)$ & $312(30.6)$ & $183(17.9)$ & $343(33.6)$ \\
\hline
\end{tabular}

\section{Results}

ANALYSIS BY MEDICAL SPECIALTY

The overall standardised emergency readmission rate for Scotland, in all medical specialties, was $10.9 \%$ for the period October 1990 to September 1994. General medicine accounted for the majority of emergency readmissions (63\% of the total in the four year period), with a rate of $10.4 \%$ (table 1 ). Emergency readmission rates varied widely between medical specialties, with the highest rates in nephrology $(24.2 \%)$ and haematology $(20.4 \%)$, and the lowest in metabolic diseases $(3.5 \%)$ and homeopathy $(2.2 \%)$.

Emergency readmission rates in the teaching hospital trusts ranged from $9.5 \%$ in trust $\mathrm{B}$, to $13.4 \%$ in trust $\mathrm{D}$, where the rate was significantly higher than other teaching hospital trusts (table 2). The range of emergency readmission rates reduced slightly when restricted to general medicine, and the rank order altered, although hospital trust D remained significantly higher than all other trusts.

\section{NUMBER OF PREVIOUS ADMISSIONS}

In the year preceding the emergency readmission, over half of all patients $(59 \%)$ had been admitted to hospital at least once, in addition to the admission relating to the emergency readmission (table 3 ). Almost one in 10 (9.2\%) had been in hospital on at least five occasions. In this high admission group, the principal cause of emergency readmission was varied, but the largest single groups were poisoning (19/94) and heart disease (15/94).

In the five year period before the emergency readmission, the proportion of patients with multiple admissions was even greater (table 3 ). Over $80 \%$ had been in hospital on at least one occasion, and $33.6 \%$ had been admitted on five or more occasions. The principal diagnoses on emergency readmission were similar, however, with the majority being related to poisoning $(60 / 343)$ and heart disease (80/343) in the group with the highest number of admissions.

ASSOCIATION BETWEEN EMERGENCY READMISSION AND PREVIOUS ADMISSION

In the sample of patients from teaching hospital trust $\mathrm{D}$, the majority of emergency readmis-

Table 4 Cause of emergency readmission within 28 days by medical specialty in a one in 10 sample, Fanuary to September 1994

\begin{tabular}{|c|c|c|c|c|c|}
\hline Specialty & $\begin{array}{l}\text { No of } \\
\text { readmissions }\end{array}$ & $\begin{array}{l}\text { Unrelated } \\
\%(n)\end{array}$ & $\begin{array}{l}\text { Complication } \\
\%(n)\end{array}$ & $\begin{array}{l}\text { Related } \\
\%(n)\end{array}$ & $\begin{array}{l}\text { Self harm } \\
\%(n)\end{array}$ \\
\hline General medicine & 113 & $22.1(25)$ & $0 \quad(0)$ & $64.6(73)$ & 13.3 \\
\hline Cardiology & 11 & $18.2(2)$ & $0 \quad(0)$ & $81.8(9)$ & $0 \quad(0)$ \\
\hline Gastroenterology & 12 & $16.7(2)$ & $0 \quad(0)$ & $83.3(10)$ & $0 \quad(0)$ \\
\hline Nephrology & 15 & $6.7(1)$ & $13.3(2)$ & $80.0(12)$ & $0 \quad(0)$ \\
\hline Haematology & 24 & $0 \quad(0)$ & $0 \quad(0)$ & $100 \quad(24)$ & $0 \quad(0)$ \\
\hline Other & 1 & $0 \quad(0)$ & $0 \quad(0)$ & $100 \quad(1)$ & $0 \quad(0)$ \\
\hline Total & 176 & $17.0(30)$ & $1.1(2)$ & $73.3(129)$ & $8.5(15)$ \\
\hline
\end{tabular}

sions $(73.3 \%)$ were clinically related to the previous admission in patients with an underlying chronic condition. In $17 \%$ the emergency readmission was completely unrelated to the previous admission (table 4). A repeated episode of self harm was responsible for emergency readmission in $8.5 \%$, but a very small proportion was readmitted because of a direct complication of treatment $(1.1 \%)$. The only direct complications of treatment were noted in nephrology, where two emergency readmissions were due to peritonitis in patients undergoing peritoneal dialysis.

The cause of emergency readmission varied only slightly between medical specialties, and any differences must be interpreted with caution because of the small numbers involved. The relative proportions of specialties in this sample generally reflected the overall figures for hospital trust D, but a greater proportion of gastroenterology patients was included $(6.9 \%$ compared with $0.9 \%, \mathrm{p}<0.01$ ).

\section{Discussion}

Significant variations in emergency readmission rates occurred between medical specialties, suggesting that differences between hospital trusts were influenced by differences in specialties and thus case mix. The majority of emergency readmissions occurred in patients with an underlying chronic condition, and many had a history of multiple previous hospital admissions. This suggests that use of the emergency readmission rate as an outcome indicator intended to reflect quality of care is ill founded, at least until better routine data are available for standardisation by quite refined detail on case mix.

ANALYSIS BY MEDICAL SPECIALTY

Large variations in emergency readmissions were shown among medical specialties throughout Scotland, with highest rates in haematology and nephrology. High rates in these specialties might have been expected because of the large number of chronically ill patients likely to require intensive treatment. Previous studies have shown relapses of an underlying medical problem to be responsible for the majority of emergency readmissions, ${ }^{19}{ }^{20}$ and that significantly more patients with chronic disabling conditions are readmitted than others. ${ }^{19}$ It has also been suggested that high readmission rates are due to a small proportion of patients with recurrent medical problems. $^{1021}$

Variation in rates between medical specialties suggests that speciality mix has an important influence on the overall emergency readmission rate for any one hospital, although general medicine has the greatest impact because most emergency readmissions are in this specialty. The key message illustrated by the large variation, however, is that the emergency readmission rate should not be used as an outcome indicator across all medical specialties unless it is either standardised for specialty mix, or restricted to certain key specialties. 
The effect of restricting the emergency readmission rate to general medicine only was shown in the teaching hospital trusts, where it reduced the range and altered the rank order, although trust D remained significantly higher than other hospital trusts. Specialty mix therefore had a significant effect on overall emergency readmission rate, and standardisation should provide a more valid comparison between hospital trusts. General medicine was selected because it contained a large number of emergency readmissions, but it should be noted that it is a fairly heterogeneous specialty. The increasing trend towards "specialism", means that at different times and in different hospital trusts, general medicine is likely to have included a different spectrum of conditions.

This supports the argument for restricting the emergency readmission rate to a specific diagnostic group, such as ischaemic heart disease, which should also further reduce variation among hospital trusts. Ideally, the emergency readmission rate would also be adjusted for severity of disease, but unfortunately this information is not routinely recorded on the SMR scheme, and therefore it cannot be done easily. An outcome indicator should be based on routinely available information so that it can be calculated and published relatively easily.

NUMBER OF PREVIOUS ADMISSIONS

This study showed that a significant proportion of patients had been admitted at least once in the previous year, and over a third had been in hospital at least five times in the previous five years. This suggests that many of those who are readmitted as emergencies have an underlying chronic condition necessitating both frequent admissions and readmissions. It may therefore be entirely appropriate that these patients are discharged home for relatively short periods, as short term breaks from hospital life. This point was made in a report by Williams and Fitton: "readmission, perhaps on several occasions, may be generally preferred to permanent admission, both by the patient and by the system". ${ }^{20}$

ASSOCIATION BETWEEN EMERGENCY READMISSION AND PREVIOUS ADMISSION

The 1 in 10 sample selected for further analysis at teaching hospital trust D was relatively small $(n=177)$ but this was larger than similar studies which have examined the avoidability of readmission. ${ }^{17}{ }^{1822-24}$ No obvious explanation exists for the relatively large proportion of gastroenterology patients in the sample, which was presumably a chance occurrence.

Emergency readmissions due to direct complications of treatment were uncommon, and occurred in only two nephrology patients who developed peritonitis as a result of peritoneal dialysis. This is a well recognised complication and is probably largely unavoidable.

Seventeen per cent of patients were readmitted with a completely unrelated condition, which is important as emergency readmissions in this group therefore bear no reflection on the previous quality of care. This represents almost one in five of the readmissions, and thus supports the argument that the emergency readmission rate is not a valid outcome indicator. Of more concern were the $8.5 \%$ of patients readmitted with a repeat episode of deliberate self harm (drug overdose, self mutilation, etc) because it is possible that better community support or follow up treatment might have prevented this.

The majority of patients, however, were readmitted with a manifestation of an underlying chronic condition, particularly chronic renal failure, leukaemia, or ischaemic heart disease. This is in accordance with previous studies which have also identified associations between readmission and underlying physical conditions ${ }^{1920}$ We are grateful to Dr Steven Kendrick at the Information and
Statistics Divisions for his help and advice on analysis of the Statistics Divisions for his help and advice on analysis of the
SMR data, and to Dr Amanda Lee who provided statistical advice.

1 Munro A. Requirements for acute beds in Scotland: the past and the future. Health Bulletin (Edinburgh) 1994:52:35-40. 2 Goldacre MJ, Simmons H, Henderson J, et al. Trends in episode-based and person-based rates of admissions to hospital in the Oxford record linkage study area. BMF 1988;269:583-5.

3 National Association of Health Authorities and Trusts. Emergency admissions: managing the rising trend. Birmingham: NAHAT, 1994.

4 Henderson J, Goldacre MJ, Graveney MJ, et al. Use of medical record linkage to study readmission rates. $B M \mathcal{F}$ 1989;299:709-13.

5 Information and Statistics Division, NHS in Scotland. Trends in hospital readmission rates in Scotland, 1983 to 1990. Edinburgh: Information and Statistics Division, Common Services Agency, 1993.

6 Saltz CC, McVey LJ, Becker PM, et al. Impact of a geriatric consultation team on discharge placement and repeat hospitalisation. Gerontologist 1988;28:344-50.

7 Outcomes Working Group of CRAG. Clinical outcome indicators report. Edinburgh: Scottish Office, 1996.

8 Kendrick S, Clarke J. The Scottish record linkage system. Health Bulletin 1993;51:72-9.

9 Jones J. Readmission rates: the price of early discharge. Health Serv f 1986; June 19:825.

10 Tierney AJ, Worth A. Review: readmission of elderly patients to hospital. Age Ageing 1995;24:163-8.

11 Kendrick $S$. The pattern of increase in emergency hospital admissions in Scotland. Health Bulletin 1996;54:169-83.

12 Census of Scotland 1981. Housing and household report. Table 30. Edinburgh: HMSO, 1991.

13 Victor C, Jefferies S. Are readmission rates a useful indicator of outcome? Geriatr Med 1990;20:19-20.

14 Williams DR. Outcome indicators for diabetic services what do we have and what do we need? Community Med 1989;11:57-64.

15 Shaw CD. Clinical outcome indicators. Health Trends 1989; 21:37-40.

16 Milne R, Clarke A. Can readmission rates be used as an outcome indicator? BMF 1990;301:1139-40.

17 Clarke A. Are readmissions avoidable? BMF 1990;301: 1136-8.

18 Popplewell PY, Chalmers JP, Burns RJ, et al. A review of early medical admissions at the Flinders Medical Centre. Aust Clin Rev 1984;11:3-5.

19 Victor CR, Vetter NJ. The early readmission of the elderly to hospital. Age Ageing 1985;14:37-42.

20 Williams EI, Fitton F. Factors affecting early unplanned readmission of elderly patients to hospital. BMF 1988;297: $784-7$.

21 Howard R. The bouncing factor. F Commun Nurs 1992;6:4-6.

22 Graham H, Livesley B. Can readmissions to a geriatric medical unit be prevented? Lancet 1983;i:404-6.

23 McInnes EG, Joshi DM, O'Brien TD. Failed discharges: setting standards for improvement. Geriatr Med 1988;18: $35-45$.

24 McDowell NM, Hunter SA, Ludke RL. Readmissions to a veterans' administration medical centre. F Qual Assurance 1985;7:20-3. 